\title{
Investigation of the effect of Crumb Rubber Additive on the Fracture of characteristics of asphalt mixtures in control and asphalt rubber mixtures
}

\author{
${ }^{1}$ Sayed Naqibullah Hashimi, ${ }^{2}$ Suhrab Ahadi and $*^{3}$ Hakan Aslan and ${ }^{4}$ Zeliha Cagla Kuyumcu \\ ${ }^{1,2}$ Faculty of Engineering, Department of Geodesy Engineering Jawzjan University, Afghanistan \\ ${ }^{* 3,4}$ Faculty of Engineering, Department of Civil Engineering Sakarya University, Turkey
}

\begin{abstract}
The failure of cracking is one of the main concerns regarding the performance of hot mix asphalt (HMA). Since the characteristic of the materials of the mixtures has impact on their cracking potential, the main conception of this research is to evaluate the effect of the type of size and additive percentage of crumb rubber modified (CRM) on the resistance of mixtures to crack at mid and low temperatures. For this purpose, rubber bitumen containing $10 \%$ and $15 \%$ crumb rubber with fine and coarse sizes with wet process was prepared. Asphalt mixtures with dense and gap grading were designed by using rubber bitumen produced by superpave method. The three-points bending test of semicircle bending sample (SCB) was used to evaluate the fracture characteristics of asphalt mixtures at low and middle temperatures $\left(25^{\circ} \mathrm{C}\right.$ and $\left.-12^{\circ} \mathrm{C}\right)$. Accordingly, the failure characteristics of asphalt mixtures were evaluated in two modes with short-term and long-term aging. The failure test results indicated that the produced mixtures with crumb rubbers additive have high resourcing resistance compared to control mixtures (without crumb rubber additive), were also revealed. Mixtures with dense grading and fine crumb rubber have high fracture resistance compared to mix with gap grading and coarse crumb rubber. Also, the increasing of the percentage of crumb rubber improved the resistance of the mixed failure. In general, it can be stated that the addition of crumb rubber increases the fracture resistance of asphalt mixtures which can improve its performance before cracking at mid and low temperatures.
\end{abstract}

Keywords: Asphalt rubber mixture, crumb rubber, wet process, cracking, fracture resistance, semicircle bending test $(\mathrm{SCB})$

\section{Introduction}

Modified bitumen is one of the most important solutions to fix pavement failure. There have been used many methods to produce modified bitumen in different modification values using different additives. In recent years, the usage of polymer has been considered as a common method in the asphalt pavement industry which can be used to improve the characteristics of bitumen. The modified bitumen can provide the widespread specifications that are needed for better road performance. Furthermore it can help the service in extreme weather and loading conditions. The application of crumb rubber obtained from waste and waste tires is one of the methods as a modifier additive. This obviously provides a valuable solution for serious environmental and climate problems. Commercial and synthetic polymers allow the production of mixtures that can withstand dealing and cracking grooves. The application of polymer additive for road construction projects depends on a variety of factors such as construction cost, ability to run, availability and expected performance. The modification of polymer of bitumen, especially in advanced countries, are more costly, because they are imported from other countries. On the other hand, the problem of the existence of used tires in the world today, is one of the major management concerns. The increase in the number of cars used as transportation mode has increased the number of additional materials such as worn tires causing large number of them to be used every year. 
The rapid expansion of the road network increased traffic and, as a result, requires engineers to devise a solution to improve the quality of the roads. Thus, by converting rubber into plastic powder and using it as an additive and modifier of bitumen functional behavior, some of the concerns about environmental issues and hence the inefficiency of asphalt mixtures will be eliminated. Asphalt rubber has unique properties in which bitumen is modified with crumb rubber because they are composed of a liquid phase and swollen particles. The swollen rubber particles affect the bitumen network by reducing the distance between the particles and eliminate the bitumen visor deficiency making it harder.

Due to the major role of roads in the national economy, it has always been considered to provide durability and increase the service life of road construction as the infrastructure facilities of each country. Bitumen and seed stone are two main components of asphalt mixture and their interaction with each other materials plays an important role in pavement performance.

In general, there are two methods for producing asphalt rubber mixtures such as: Dry and wet process. In the dry process, coarse-grained crushed rubber (with particle sizes between 0.4 and $10 \mathrm{~mm}$ ) is typically mixed with granular aggregates to replace a small portion of aggregates (usually 1 to $3 \%$ of the total weight of stone materials) and then bitumen is added to produce asphalt mixture containing crumb rubber. In wet method, fine rubber bitumen and powder are mixed under certain temperature and time conditions to produce rubber bitumen. In the following, the asphalt rubber mixtures are obtained by mixing the rubber bitumen. Rubber bitumen and powder are usually mixed at temperatures above $180^{\circ} \mathrm{C}$ for one to several hours by a mixer. At such a high temperature, many physical and chemical bonds are established between the components. During this process, the viscosity of bitumen is increased to reach a constant level. A reasonable constant viscosity indicates the completion of the reaction. The reaction of crumb rubber with bitumen depends on the mixing temperature, mixing time, mixer type, size and shape of crumb rubber particles and the type of base bitumen [1]. The main reaction (or interaction) between crumb rubber and tire is physical type. As a result of the interaction, the particles of crumb rubber absorb part of the light oils in the bitumen and thereby inflatable to obtain rubber bitumen that has a high viscosity jelly appearance. The amount of swelling and its size depends on the mixing temperature [2].It should be noted that, it is possible to reduce the viscosity due to the degradation of the structure of inflated crumb rubber particles with prolonged mixing time or storage. Researches show that adding crumb rubber to bitumen increases 1 to 2 functional categories at high temperatures and increases the range of functionality. In most researches, it was observed that changing the functional category of low temperature of bitumen due to the use of crumb rubber depends heavily on the type of base bitumen [3] while other research results show that the functional category is stable at low temperature [4]. Adding crumb rubber along with increasing the functional range of bitumen has other advantages before fatigue cracks [5], and increased resistance to grooves [6].

Among several methods and tests of asphalt mixture failure, semicircular bending test (SCB) due to efficiency, reproducibleness, possibility of creating different modes of failure and practical methods to determine the behavior and failure of asphalt concrete has attracted attention to the asphalt pavement society [7]. The results of the semicircular bending test indicate the effect of variables such as loading rate, sample thickness and experiment of temperature in the test [8]. The failure characteristics of the cracked asphalt mixture are not considered and factors such as the type of traffic passing, the speed of the passing vehicles, and the grading of the sample are not taken into line with the actual conditions that can affect the results of the studies [9]. Therefore, this study shows that investigating the mechanics of failure and fatigue of asphalt mixture by using loadings close to real conditions at different speeds and 
different grading is of great importance. The question of "What is the effect of adding plastic pour on the specialty of asphalt mixtures?" Is an important question to be answered which is the main scope of this paper?

\section{Materials and Methods}

The materials used in this research include aggregate, bitumen and crumb rubber, the characteristics and features of each of which are described in detail below.

\subsection{Specifications of Usable Materials}

The seeds used in this study were prepared from Aspcharan Mine (Company of Kandovani-epars) located in northeast of Tehran. The materials in this mine include three types of coarse grains (4.75 to $12.5 \mathrm{~mm}$ ), fine-grained (smaller than $4.75 \mathrm{~mm}$ ) and filler. These materials are made of limestone.

The bitumen used in this study is a 60-70 penetration grade prepared by Pasargad Oil Company of Tehran. It is important to state that this bitumen has the performance of grade of PG64-22 based on Sharp's performance classification.

The results of the experiments on these materials are listed in Table 1.

Table 1. Specific gravity and water absorption percentage of stone and bitumen materials

\begin{tabular}{|c|c|c|c|}
\hline \multirow{2}{*}{$\begin{array}{c}\text { Percentage of } \\
\text { water } \\
\text { absorption }\end{array}$} & Real & Apparent & \multirow{2}{*}{ Description } \\
\cline { 2 - 3 } 0.9 percentage & 2.657 & 2.687 & Stone materials left on the score 8 (AASHTO T85) \\
\hline 1.8 percentage & 2.621 & 2.728 & Stone materials rejected from sieving score 8 and residual sieve \\
200 (AASHTO T84)
\end{tabular}

Table 2. Bitumen specifications

\begin{tabular}{|c|c|c|c|}
\hline $\begin{array}{c}\text { The result of } \\
\text { experiment }\end{array}$ & Standard of experiment & Type of experiment & $\begin{array}{c}\text { The type of bitumen to } \\
\text { be tested }\end{array}$ \\
\hline 62.3 & ASTM D5-97 & Penetration Degree Test & \multirow{2}{*}{ Pure bitumen } \\
\cline { 1 - 3 } 54 & ASTM D36-95 & $\begin{array}{c}\text { Soft grade determination } \\
\text { test }\end{array}$ & \\
\hline $140<$ & ASTM D113-99 & Ductility Test & \\
\hline
\end{tabular}

\subsubsection{Grading}

In order to cover a wide range of grading used in executive activities, the present study has used dense and gap grading [10]. The granular grading used in this study is shown in Table 3. 
Table 3. Dense and gap usable granular grading

\begin{tabular}{|c|c|c|c|c|c|c|c|c|c|c|c|c|}
\hline & $\begin{array}{c}\text { Size of } \\
\text { sieve } \\
\text { (mm) }\end{array}$ & 25.4 & 19 & 12.5 & 9.5 & 4.75 & 2.36 & 0.85 & 0.6 & 0.3 & 0.15 & 0.075 \\
\hline Dense & $\begin{array}{c}\text { Pass } \\
\text { percentage } \\
\text { range }\end{array}$ & 100 & $\begin{array}{c}90- \\
98\end{array}$ & $70-$ & - & $\begin{array}{c}42- \\
58\end{array}$ & $\begin{array}{c}29- \\
43\end{array}$ & - & $\begin{array}{c}10- \\
23\end{array}$ & - & - & $2-7$ \\
\hline $\begin{array}{c}\text { Pass } \\
\text { percentage } \\
\text { ne each } \\
\text { sieve }\end{array}$ & 100 & 98 & 84 & 72 & 47 & 28 & 16 & 12 & 8 & 6 & 4 \\
\hline Gap & $\begin{array}{c}\text { Pass } \\
\text { percentage } \\
\text { range }\end{array}$ \\
Gap & $\begin{array}{c}\text { Pass } \\
\text { percentage } \\
\text { in each } \\
\text { sieve }\end{array}$ & 100 & 100 & $90-$ & $83-$ & $28-$ & $14-$ & - & - & - & - & $0-6$ \\
\hline
\end{tabular}

After selecting the grading, the optimum bitumen value for each grading was obtained using superpave method $[11,13]$. According to the design of the asphalt mixture by superpave method, the percentage of bitumen corresponding to the air level of $4 \%$ in the mixture is the optimum bitumen percentage. In order to get the optimum bitumen, samples with different percentages of bitumen should be prepared by performing the relevant weight-volume calculations. The amount of optimum bitumen should be obtained by interpolation. The percentage of bitumen corresponding to the air level of $4 \%$, equal to $96 \%$ of the maximum theoretical specific weight $\left(\mathrm{G}_{\mathrm{mm}}\right)$, in the number of $\mathrm{N}_{\text {des }}$ rotation (in this study 100) was the criterion for selecting the optimum percentage of bitumen. Of course, other weight-volume properties such as specific gravity, percentage of space in mineral materials (VMA), percentage of space filled with bitumen (VFA) and proportion of dust (DP) should also be controlled for optimum bitumen percentage [14]. According to the estimated amount of bitumen, four different percentages of bitumen were selected for each grading. Dense grading of samples with bitumen percentages of 4.5, 5, 5.5 and 6 were produced and optimum bitumen was selected according to Table 3,5.6\%. Also, with the open grading including rubber powder, samples with percentages of bitumen $7,7.5,8$ and 8.5 were made and according to Table 4, optimum bitumen was selected $8.5 \%$.

Table 4. Weight-volume characteristics of dense gradation

\begin{tabular}{|c|c|c|c|c|c|c|}
\hline Table 4. Weight-volume characteristics of dense gradation \\
\hline \multirow{2}{*}{$\begin{array}{c}\text { Specification of weight } \\
\text { volume }\end{array}$} & \multirow{2}{*}{$\begin{array}{c}\text { Standard } \\
\text { Stand }\end{array}$} & \multicolumn{5}{|c|}{ Percentage of bitumen (\%) Dense grading } \\
\cline { 3 - 7 } & 4.5 & 5 & 5.5 & 5.6 & 6 \\
\hline Percentage of the air & 4 & 6.7 & 5.9 & 4.35 & 4 & 3.36 \\
\hline Percentage of VMA & $13>$ & 16.27 & 16.64 & 16.28 & 15.41 & 16.36 \\
\hline Percentage of VFA & $65-75$ & 58.81 & 64.54 & 73.28 & 74.04 & 79.46 \\
\hline Percentage of DP & $0.6-1.2$ & 0.88 & 0.8 & 0.72 & 0.72 & 0.66 \\
\hline
\end{tabular}


Table 5. Weight-volume characteristics of dense gradation

\begin{tabular}{|c|c|c|c|c|c|}
\hline \multirow{2}{*}{$\begin{array}{c}\text { Specification } \\
\text { of weight } \\
\text { volume }\end{array}$} & \multirow{2}{*}{$\begin{array}{c}\text { Standard } \\
\text { stand }\end{array}$} & \multicolumn{4}{|c|}{ Percentage of bitumen (\%) gap grading } \\
\cline { 3 - 6 } & 4 & 6.4 & 7.5 & 8 & 8.5 \\
\hline $\begin{array}{c}\text { Percentage of } \\
\text { air }\end{array}$ & $13>$ & 18.36 & 18.62 & 17.79 & 15.61 \\
\hline $\begin{array}{c}\text { Percentage of } \\
\text { VMA }\end{array}$ & $65-75$ & 65.14 & 67.77 & 71.89 & 74.37 \\
\hline $\begin{array}{c}\text { Percentage of } \\
\text { VFA }\end{array}$ & & & & & 4 \\
\hline
\end{tabular}

In order to produce asphalt mixtures in this study, stone materials were placed at $165^{\circ} \mathrm{C}$ along with bitumen at $155^{\circ} \mathrm{C}$ then mixed together. The mixing process was carried out to obtain a uniform mixture in which all stone materials are completely covered with bitumen. The resulting mixtures were condensed at $135^{\circ} \mathrm{C}$ by rotational compaction device to make mixed design samples and samples needed for functional tests.

\subsubsection{Crumb rubber}

The crumb rubber used in this study was prepared for two sizes: coarse grain (1-3 mm) and fine sieve size $30(0.6 \mathrm{~mm})$ from Mehrfaneh Tejarat Company.

\subsubsection{Mixing percentage of materials}

As there have been many experiments, which were done based on recycled crumb rubber and its effects on pure bitumen; the optimum mixing percentage with pure bitumen is 10 to 18 percent. However, in the samples used in this study, the percentage of crumb rubber was $10 \%$ and $15 \%$.

\subsection{Manufacturing asphalt rubber samples}

In this research, to produce asphalt rubber samples, firstly rubber bitumen was prepared by a high shear, then asphalt rubber mixtures were prepared, and finally asphalt rubber samples were prepared by a gyratory compaction machine.

\subsubsection{Sieve and material gradation}

In order to make the sample, the materials must be sieved first so that the desired sample can be made obtained. For grading and separation of grain stones, a laboratory shaker with a diameter of $30 \mathrm{~cm}$ was used. In order to sieve the materials with size of $25.4 \mathrm{~mm}, 19 \mathrm{~mm}$, $12.5 \mathrm{~mm}, 9.5 \mathrm{~mm}, 4.75 \mathrm{~mm}$ (sieve \#4), $2.36 \mathrm{~mm}$ (sieve \#8), $0.85 \mathrm{~mm}$ (sieve \#20), $0.3 \mathrm{~mm}$ (sieve \#50), $0.75 \mathrm{~mm}$ (sieve \#100), 75 micron (sieve \#200) and under sieve were used.

After the desired materials were sieved, each must be poured to the separated cell, and the materials must be washed, in this case all the materials, were washed excepting the materials with the no \#200 and also the passing materials \#200. The washing was done because the filler materials on the stone that are unearthed do not cause fillers with different percentages in each sample. After washing the materials, they are spread over the plastic to make the free air flow dry as much as possible and lose the moisture from washing. 
To select the grain curvy limits, a report by the UCPRC ${ }^{1}$ was selected for dense and gap grading of asphalt mixtures [10]. While dense grading has a maximum nominal size of $19 \mathrm{~mm}$, interrupted grading has a maximum nominal size of $12.5 \mathrm{~mm}$.

\subsection{The way of mixing crumb rubber and bitumen}

In this study, crumb rubber was used to crush the worn tires of cars at the produced ambient temperature. ASTM D6114-49 standard was used to determine the particle size of rubber powder. For bitumen modification, $10 \%$ and $15 \%$ crumb rubber with particle size of 30 and 13 at $170^{\circ} \mathrm{C}$ with base bitumen was mixed at Kandovan Pars Company and soil mechanics laboratory technical company with high cutting mixing machine. The mixer speed was 3000 round per minute and the mixing time was $60 \mathrm{~min}$. The structure of durable stone materials increases the resistance of asphalt mixtures against deformation due to repeated load. Stone and grading materials have a significant effect on the strength and yield of asphalt mixtures. It is obvious that the physical characteristics of the grain stones significantly affect the pavement performance. The stone materials which are used in order to prepare the asphalt mixture should be clean and free of any dust. Coarse sand and stone materials are bearing components in asphalt mixtures. Several factors affect the bond between bitumen and stone materials such as the shape of the beads (angled or rounded corner), the absorption capacity of bitumen (porous or non-porous) and the degree of acidity.

\subsubsection{Temperatures}

All samples were prepared at $165^{\circ} \mathrm{C}$. The increase of the viscosity of bitumen through using rubber powder changes the temperature of mixing asphalt with grain stone. Furthermore, to ensure proper mixing, the fabrication temperature was set at $165{ }^{\circ} \mathrm{C}$ for all samples. It should also be noted that the density temperature is placed in mixtures as more than $150{ }^{\circ} \mathrm{C}$ to achieve the percentage of standard empty space.

\section{Determination of maximum Asphalt Mixture weight test $\mathbf{G}_{\mathrm{mm}}$}

In order to determine the optimum bitumen percentage, maximum density of asphalt mixture is required. Rice test is used to determine this parameter. Therefore, $\mathrm{G}_{\mathrm{mm}}$ determination test is necessary to obtain design parameters such as actual specific gravity of sample, percentage of sample empty space, percentage of empty space of grain stone, percentage of optimum bitumen and finally to introduce the required parameters in generator software for condensation.

The $\mathrm{G}_{\mathrm{mm}}$ value is dependent on the characteristics of grade, gradation, bitumen and additives and changes in each of the mentioned variables and assuming that other parameters remain constant. Therefore, for a genus of granular stone with the percentage of pure bitumen and rubber bitumen $\mathrm{G}_{\mathrm{mm}}$ can be obtained. Assuming that the grading remains constant, $\mathrm{G}_{\mathrm{mm}} \mathrm{mix}$ for other percentages of pure bitumen and rubber bitumen can also be obtained with the help of weighted-volume mathematical relationships. One of the most important goals in this research is to determine the percentage of optimum bitumen to make sure that rice test has been done for pure bitumen and rubber bitumen.

\footnotetext{
${ }^{1}$ University of California, California Pavement Research Center
} 
This test is carried out according to ASTM D20-41 [10]. According to The Archimedes laws, the sample size is equal to the mass of the sample in the air plus the mass of the Erlen filled with water, the mass of the Erlen contains the sample and the water.

$\mathrm{H}=\mathrm{C}+\mathrm{D}-\mathrm{E}$

In the $1^{\text {st }}$ equation, the sample volume is shown.

The sample specific gravity $\left(\mathrm{G}_{\mathrm{mm}}\right)$ is obtained from the following equation.

$\mathrm{G}_{\mathrm{mm}}=\mathrm{C} . \mathrm{H}$

In order to obtain the optimum bitumen percentage, it is necessary to calculate $G_{\mathrm{mm}}$ for all percentages to avoid repeating rice test for all samples. For this purpose, a parameter called the effective specific gravity of all $\mathrm{G}_{\mathrm{se}}$ stone materials is used. So, for a specific percentage of bitumen may be attained by calculating $G_{\mathrm{mm}}$ and $\mathrm{G}_{\mathrm{se}}$ for other percentages. $\mathrm{G}_{\mathrm{se}}$ is calculated from the $3^{\text {rd }}$ relationship.

$\mathrm{G}_{\mathrm{se}}=\frac{100-P b}{\frac{100}{G m m}-\frac{P b}{G b}}$

The $4^{\text {th }}$ equation below is used to determine $\mathrm{Gmm}$ for different percentages of bitumen.

$\mathrm{G}_{\mathrm{mm}}=\frac{100}{\frac{100-p b}{G s e}+P b / G b}$

In the above relationship, $\mathrm{P}_{\mathrm{b}}$ and $\mathrm{G}_{\mathrm{b}}$ indicate the percentage of bitumen and the specific gravity of bitumen, respectively.

The experiment took place as described and the results are revealed below. This experiment was carried out for pure bitumen 5\%, rubber bitumen with continuous gradation of 5\% and for rubber bitumen with $7 \%$ interrupted grading with three replications to minimize the test errors.

The results of the experiment are as follows:

Asphalt mixture with continuous grading with $5 \%$ bitumen

Maximum mixed density for the first time $\mathrm{G}_{\mathrm{mm}}=2.435$

Maximum mixed density for repeating $\mathrm{G}_{\mathrm{mm}}$ test $=2.437$

Maximum mixed density for repeating $\mathrm{G}_{\mathrm{mm}}$ test $=2.436$

Asphalt rubber mixture with interrupted grading with $7 \%$ bitumen

Maximum mixed density for the first time $\mathrm{G}_{\mathrm{mm}}=2.366$

Maximum mixed density for repeating $\mathrm{G}_{\mathrm{mm}}$ test $=2.367$

Maximum mixed density for repeating $\mathrm{G}_{\mathrm{mm}}$ test $=2.365$

The difference which should be less than 0.023 for an operator in a test according to ASTM D20-41 standard obtained for three replications is very small, hence acceptable. In order to minimize the test error, all three samples of conventional and asphalt rubber mixtures are averaged. Therefore:

$\mathrm{G}_{\mathrm{mm}(\text { dense })}=2.436$

$\mathrm{G}_{\mathrm{mm}(\mathrm{gap})}=2.366$ 
the maximum density 2.436 for the sample with bitumen is $5 \%$ and 2.366 is the maximum density for the sample with 7\% bitumen. As mentioned above, for the Equation 3 of the total gravity of $\mathrm{G}_{\mathrm{se}}$ stone materials are used in order to have no needs to calculate the maximum density again. The specific gravity of bitumen is 1.025 .

Based on the estimated percentage of $5 \%$ bitumen, $4 \%, 4.5 \%, 5 \%, 5.5 \%$ and $6 \%$ bitumen were prepared in order to receive the optimum bitumen percentage for mixtures with continuous grading. In addition, in order to determine the optimum bitumen percentage of asphalt rubber mixture with interrupted gradation based on the estimated percentage of $7 \%$ bitumen mixtures with $7 \%, 7.5 \%, 8 \%$ and $8.5 \%$, each $\mathrm{G}_{\mathrm{mm}}$ was obtained using the The above formulas in table 5 and table 6.

Table 6. Maximum density of asphalt mixtures with dense gradation

\begin{tabular}{|c|c|}
\hline Percentage of bitumen & Maximum density of mixture $\mathrm{G}_{\mathrm{mm}}$ \\
\hline 4.5 & 2.455 \\
\hline 5 & 2.436 \\
\hline 5.5 & 2.418 \\
\hline 6 & 2.401 \\
\hline 5.6 & 2.416 \\
\hline
\end{tabular}

Table 7. Maximum density of asphalt mixtures with gap gradation

\begin{tabular}{|c|c|}
\hline Percentage of bitumen & Maximum density of mixture $\mathrm{G}_{\mathrm{mm}}$ \\
\hline 7 & 2.367 \\
\hline 7.5 & 2.350 \\
\hline 8 & 2.334 \\
\hline 8.5 & 2.318 \\
\hline
\end{tabular}

\section{Determination of optimum bitumen content}

According to the design of the asphalt mixture by superpave method, the percentage of bitumen corresponding to the air level of $4 \%$ in the mixture is the optimum bitumen percentage. Therefore, in order to get the optimum bitumen, samples with different percentages of bitumen should be made and by performing the relevant weight-volume calculations, the amount of optimum bitumen should be obtained by interpolation. The percentage of bitumen corresponding to the air level of $4 \%$ in $\mathrm{N}_{\text {des }}$, which was equal to $96 \% \mathrm{G}_{\mathrm{mm}} @ \mathrm{~N}_{\mathrm{des}}$, was the optimal percentage selection criterion. Of course, mechanical properties such as specific gravity, the percentage of space in mineral materials (VMA), the percentage of space filled with bitumen (VFA) and the proportion of dust (DP) may also be a good criterion for the optimum bitumen percentage [14]. In this study, the Gyratory Compaction density method was used to obtain the optimum bitumen percentage. Grading is the interrupted percentage of bitumen in which $\mathrm{N}_{\text {des }}$ reach $4 \%$ free space between 50 and 150 gyration. 


\subsection{Making samples for original tests}

After confirmation of optimum bitumen percentage, in this section, the sample is made for the main experiments. Another parameter that has been evaluated in this study is aging. Aging is divided into short-term aging and long-term aging. Short-term aging is called bitumen oxidation during the transportation and implementation of asphalt pavement, while long-term aging during the service life of the pavement is due to the heat given to the pavement. The reason for considering this parameter in this study was its significant effect on the failure behavior of asphalt mixtures. For short-term aging, asphalt samples are placed at $135^{\circ} \mathrm{C}$ before condensation for 4 hours and then the condensation is performed on it [15]. There are different methods for long-term aging in this study using the newly published NCHRP 09-54 code of conduct [16]. According to this regulation, for long-term aging, the asphalt density sample is placed at $85^{\circ} \mathrm{C}$ for 5 days. This rate indicates aging over several years in reality.

\subsection{Semi-circular sample flexural loading test}

After simulating aging, the asphalt mixture sample was cut with a blade and a thickness of 3 $\mathrm{mm}$. At first, cylindrical samples of asphalt mixture with a diameter of $152.4 \mathrm{~mm}$ (6 inches) are cut in such a way that from each sample three circular discs with a thickness of $50 \mathrm{~mm}$ are obtained. Then the disc divided into half circles and a $15 \mathrm{~mm}$ groove is created in the center of each of these semicircles. It should be pointed that in this study, the created grooves are perpendicular to the sample diameter. As it is mentioned above, to calculate the parameter and require three different groove lengths. For this purpose, SCB samples are usually made with three groove lengths of $25.4,31.75$, and $38.1 \mathrm{~mm}$ (1, 1.25 and 1.5 inch).

Semicircle bending loading test (SCB) is one of the common tests of failure mechanics in which the cracked semicircle specimen is exposed to three-point flexural loading (1). In this study, loading of asphalt sample is exposed to failure in open conditions. Using symmetric support and considering the ratio of support spacing to sample, diameter equal to $0.6(\mathrm{~S} / \mathrm{D})$ was used. Then, SCB samples were exposed to monotonic load. After preparing the semicircle sample of asphalt mixture, this sample was subject to fixed-rate monotonic loading at -25 and $-12{ }^{\circ} \mathrm{C}$. The loading rate was $0.5 \mathrm{~mm}$ and the sample loading continued until the banding. The existence of the groove causes the concentration of tension to be at the edge of the groove and the crack begins from the edge of the groove. Figure 1 shows the semicircle sample of the asphalt mixture during testing. For this purpose, the resistance device of asphalt mixtures of bitumen laboratory and asphalt mixtures of $\mathrm{UT}^{2}$ was used.
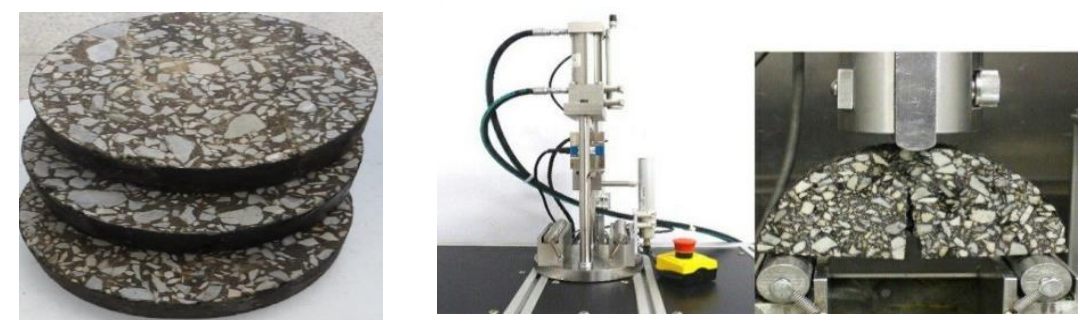

Figure 1. Cut and load samples

\footnotetext{
${ }^{2}$ University of Tehran
} 


\section{Results}

Figures 2, 3 and 4 illustrate the failure characteristics of asphalt mixtures obtained from SCB testing on all asphalt samples. In general, it can be observed that independent of the test temperature and aging conditions, asphalt rubber mixtures have higher fracture energy and higher fracture resistance compared to the control mixture. These results generally indicate the positive effect of modification of bitumen characteristics with rubber in order to improve the performance of asphalt mixtures against cracking at middle temperatures (mostly due to fatigue) and at low temperatures (mostly due to temperature) and during pavement life (considering long-term aging conditions). Improvements in fracture energy from 0.37 to 0.70 $(\mathrm{KJ} / \mathrm{m} 2)$ and in fracture resistance from 0.645 to $0.750 \mathrm{Mpa} \cdot \mathrm{m}^{05}$ can be expected depending on the type of asphalt rubber mixture.

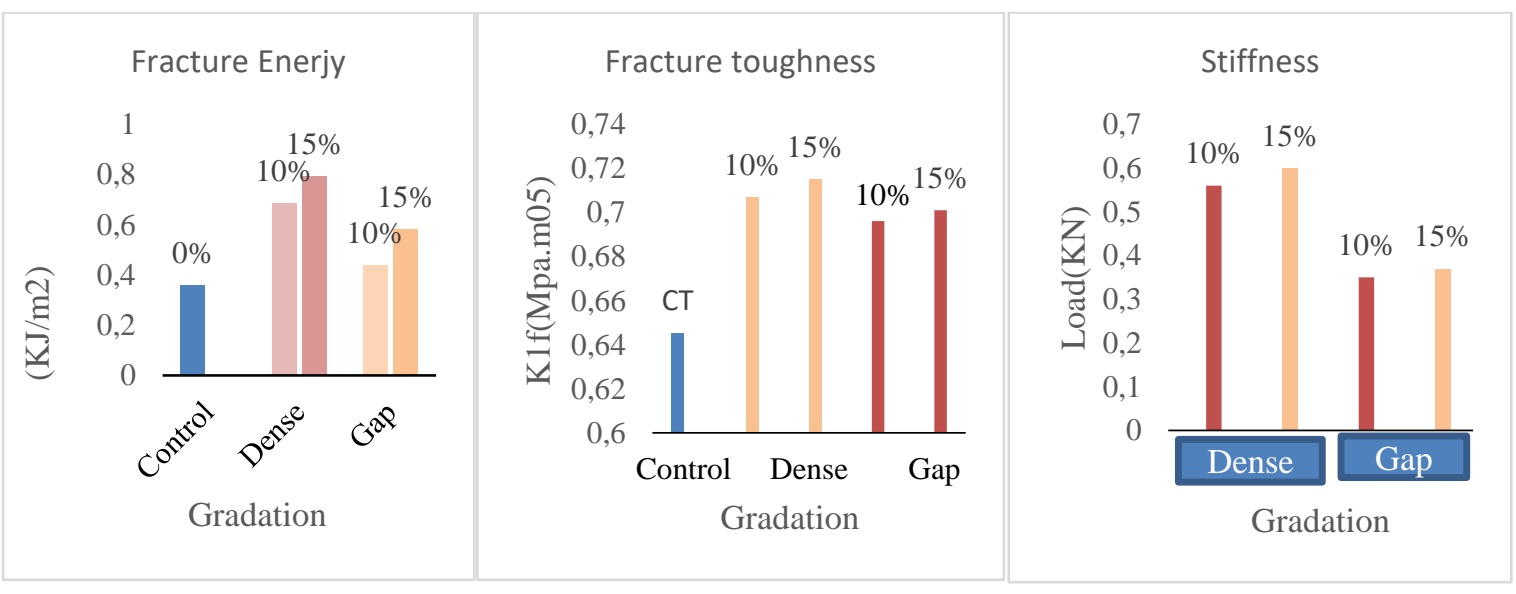

Figure2. The effect of gradation against fracture energy, fracture resistance and stiffness

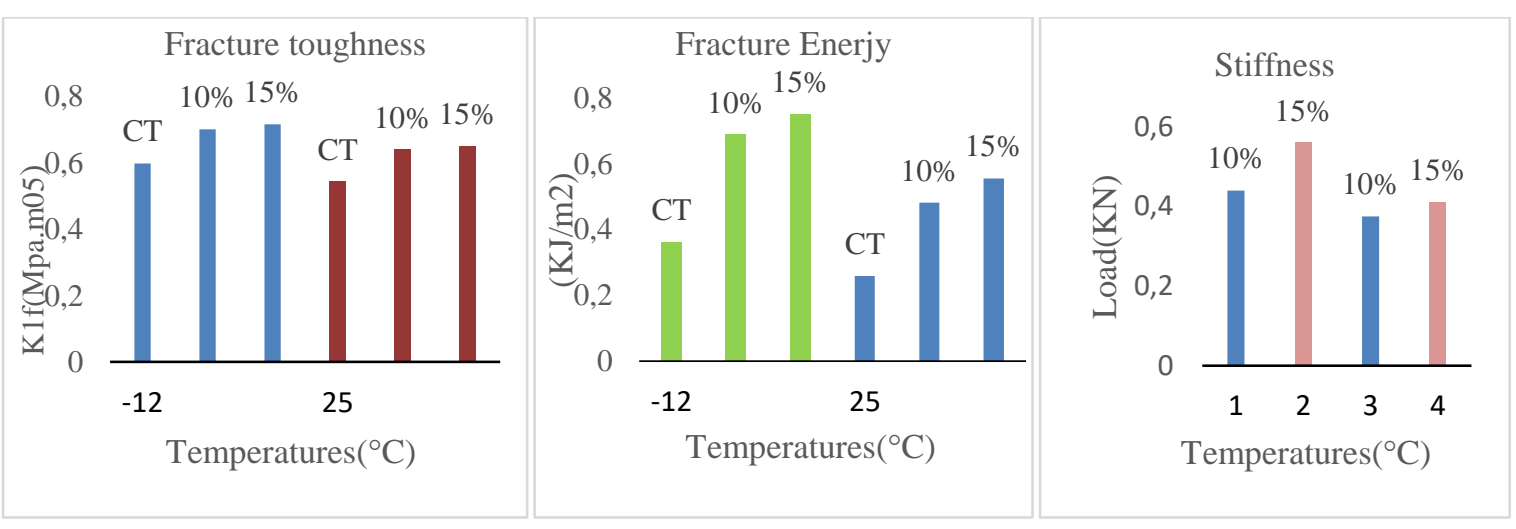

Figure3. The effect of temperatures against fracture energy, fracture resistance and stiffness 

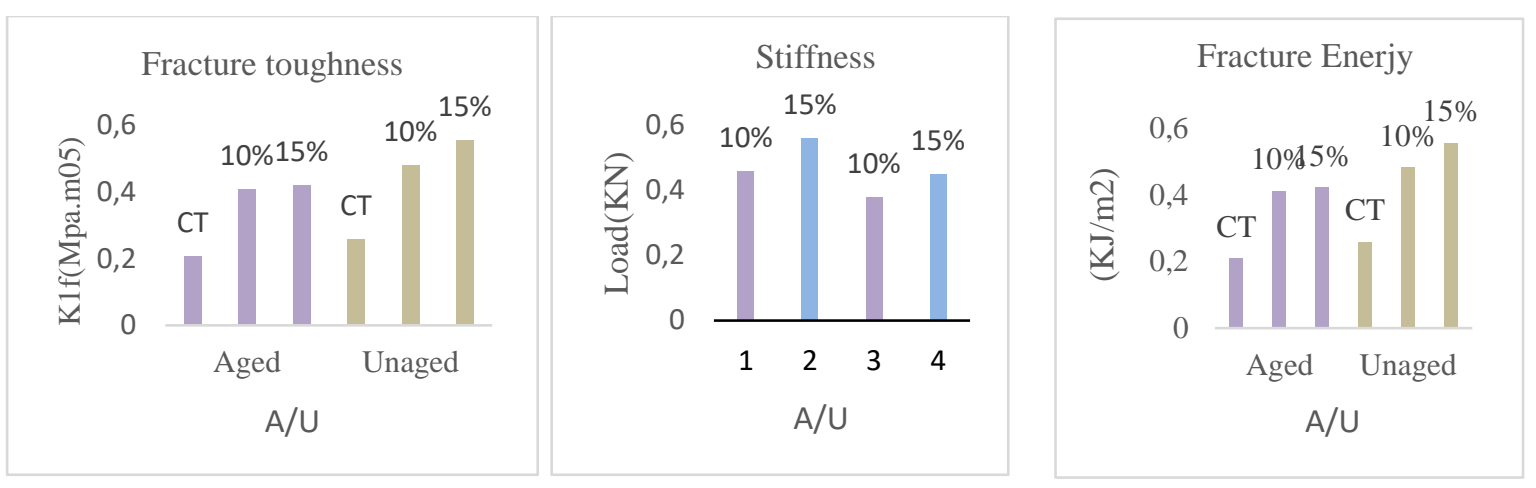

Figure4. The effect of aging or unaging $\left(\mathrm{A} / \mathrm{U}^{3}\right)$ against fracture energy, fracture resistance and stiffness

\section{Conclusion}

Low temperature cracking is one of the most common causes of failure in asphalt pavements. Failure to repair cracked pavement on time can cause crack expansion and other failures in the asphalt layer. Considering that the pavement used in most roads is asphalt pavement, accurate determination of the causes and mechanisms of cracking and finding a solution to increase the resistance of asphalt cracking is acrucial.

1- In this study, the asphalt mixtures were made by a gyro-density device while semicircle samples were prepared using a cutting machine.

2- In order to compare and investigate the effect of crumb rubber on increasing the failure of asphalt mixtures, five types of asphalt samples (control asphalt samples, asphalt rubber samples with continuous grading and with $10 \%$ and $15 \%$ fine crumb rubber and asphalt rubber samples with gradation and with $10 \%$ and $15 \%$ coarse-grained rubber powder) were prepared and tested.

3- The results of SCB test showed that adding crumb rubber to bitumen significantly improves the ability of asphalt mixture to deal with the spread of cracking at the middle temperature. It was also observed that this improvement gets better with increasing the percentage of rubber powder. The results showed that with the addition of 10 and 15 percent of rubber powder, the mixed fracture energy increased from 0.68 to 0.78 , respectively.

5- The results expressed the fact that the use of crumb rubber has a significant effect on increasing the defeat energy of asphalt mixtures and its use improves the performance of asphalt procedures by increasing the resistance to cracking growth.

\footnotetext{
${ }^{3}$ Aging/Unaging
} 


\section{References}

[1] Farouk, A. I. B. et al. Effects of mixture design variables on rubber-bitumen interaction: properties of dry mixed rubberized asphalt mixture. Mater. Struct. Constr. 50, 1-10 (2017).

[2] Hassan, N. A., Airey, G. D., Jaya, R. P., Mashros, N. \& Aziz, M. A. A review of crumb rubber modification in dry mixed rubberised asphalt mixtures. J. Teknol. 70, 127-134 (2014).

[3] Kim, Y. R. \& Wen, H. Fracture energy from indirect tension testing. Asph. Paving Technol. Assoc. Asph.Paving Technol. Tech. Sess. 71, 779-793 (2002

[4] Tabatabaee, N., Sabouri, M., Tabatabaee, H. \& Teymourpour, P. Evaluation of performance grading parameters for crumb rubber modified asphalt binders and mixtures. Adv. Test. Charact. Bitum. Mater. 1-11 (2009). doi:10.1201.9780203092989.ch58

[5] Tabatabaee, N. \& Tabatabaee, H. A. Multiple stress creep and recovery and time sweep fatigue tests: Crumb rubber modified binder and mixture performance. Transp. Res. Rec. 67-74 (2010). doi:10.3141.2180-08

[6] Nejad, F. M., Aghajani, P., Modarres, A. \& Firoozifar, H. Investigating the properties of crumb rubber modified bitumen using classic and SHRP testing methods. Constr. Build. Mater. 26, 481-489 (2012).

[7] Pirmohammad, S. \& Ayatollahi, M. R. Fracture resistance of asphalt concrete under different loading modes and temperature conditions. Constr. Build. Mater. 53, 235-242 (2014).

[8] Pérez-Jiménez, F., Botella, R., Moon, K. H. \& Marasteanu, M. Effect of load application rate and temperature on the fracture energy of asphalt mixtures. Fénix and semi-circular bending tests. Constr. Build. Mater. 48, 1067-1071 (2013).

[9] Sarkar, A. Combined effect of loading pattern, pulse duration, and stress level on the cyclic creep test of asphalt mixture. J. Mater. Civ. Eng. 29, 1-8 (2017).

[10] UCPRC-RR. Preliminary Investigation into the Use of Reclaimed Asphalt Pavement in Gap-Graded Asphalt Rubber Mixes, and Use of Reclaimed Asphalt Rubber Pavement in Conventional Asphalt Concrete Mixes. (2016).

[11] ALDOT-307-83. DESIGN METHOD FOR SELECTING OPTIMUM ASPHALT CEMENT CONTENTOF HOT-MIX ASPHALT BY MEANS OF THE MARSHALL APPARATUS.(2008).

[12] N.Paul, K. \& S., S. EVALUATION OF THE EFFECTS OF MIXTURE PROPERTIES AND COMPACTION METHODS ON THE PREDICTED PERFORMANCE OF $S$ UPERPAVE MIXTURES by N . Paul Khosla S . Sadasivam FINAL REPORT FHWA . NC . 2002-030 in Cooperation with North Carolina Department of Transportation De. (2002)

[13] [USA] MS-2. ASPHALT MIX DESIGN METHODS (7TH EDITION) 2014.

[14] Tx DOT Designation: Tex-227-F. Theoretical Maximum Specific Gravity of Bituminous Mixtures.(2019).

[15] AASHTO R 30. STANDARD PRACTICE FOR MIXTURE CONDITIONING OF HOT MIX ASPHALT.

[16] NCHRP 09-54. Long-Term Aging of Asphalt Mixtures for Performance Testing and Prediction. (2013). 